\title{
Perspectiva del fraude a subvención en el derecho colombiano: un análisis desde la función pública
}

Perspective of a subsidy fraud in Colombian law. An analysis from the public service

Autores: Daniel Rigoberto Bernal Gómez, Duván Stiven Díaz Bejarano

DOl: https://doi.org/10.19053/16923936.v19.n38.2021.13693

Para citar este artículo:

Bernal Gómez, D. R., y Díaz Bejarano, D. S. (2021). Perspectiva del fraude a subvención en el derecho colombiano: un análisis desde la función pública. Derecho y Realidad, 19 (38), 95-112. 


\title{
Perspectiva del fraude a subvención en el derecho colombiano: un análisis desde la función pública
}

\author{
Perspective of a subsidy fraud in Colombian law. An analysis from the public service
}

\section{Daniel Rigoberto Bernal Gómez}

Doctor en Derecho (c) Universidad de Mar del Plata Argentina, Doctor en Derecho Público (c) Universidad Santo Tomas. Magister en Derecho Administrativo Universidad Libre de Colombia. Especialista en Derecho Privado Económico y Abogado Universidad Nacional de Colombia. Docente Investigador Grupo Fundador semillero Aurora del Saber, del Grupo de Investigación Justicia Social Primo Levi (B) Universidad Pedagógica y Tecnológica de Colombia.

E-mail daniel.bernal02@uptc.edu.co. Orcid: https://orcid.org/0000-0002-4223-0678

\section{Duván Stiven Díaz Bejarano}

Estudiante semillero de investigación. Integrante semillero Aurora del Saber, del Grupo de Investigación Justicia Social Primo Levi (B) Facultad de Derecho Universidad Pedagógica y Tecnológica de Colombia e-mail: duvan.diaz@uptc.edu.co.

Orcid: https://orcid.org/0000-0001-7004-4226

Recepción: Marzo 30 de 2021

Aceptación: Abril 23 de 2021

\section{RESUMEN}

La corrupción administrativa es un fenómeno recurrente en muchos ordenamientos jurídicos. En este sentido Colombia no escapa a estas desafortunadas maniobras realizadas por particulares y servidores públicos. El presente artículo es una revisión jurídica del fenómeno del fraude a subvención a través de la reflexión de este, usando el método sintético. Primero, haciendo una introducción al marco constitucional de separación de poderes del Estado de Derecho Colombiano y, segundo, tomando el referente doctrinal y de derecho

comparado, para concluir con algunos precedentes jurisprudenciales de impacto al ordenamiento jurídico colombiano.

\section{PALABRAS CLAVES}

Corrupción; derecho administrativo; función pública; subvención; derecho penal.

\section{ABSTRACT \\ Administrative corruption is a recurring phenomenon in many legal systems. In this}

\footnotetext{
* Artículo de Revisión de derecho comparado en el marco de la Función pública del Derecho Administrativo colombiano, su relación con el tipo penal Fraude de Subvenciones en la legislación penal, de países integrantes de la U.E. y conexidad con la figura abuso del derecho desarrollada por la Jurisdicción Constitucional y Ordinaria.
} 
respect Colombia does not escape these unfortunate maneuvers made by individuals and public servants. This article is a legal review of the phenomenon of subsidy fraud through reflection on it, using the synthetic method, first making an introduction to the constitutional framework of separation of powers of the Colombian State of Law, then in a second section it is taken the doctrinal and comparative law reference, to conclude with some jurisprudential precedents of impact on the Colombian legal system.

\section{KEYWORDS}

Corruption; Administrative Law; Civil service; Subventions; Criminal Law.

\section{INTRODUCCIÓN}

La organización del Estado colombiano se erige sobre la división de poderes compuestas por la rama legislativa, ejecutiva y judicial. Ocupándonos de estas dos últimas con la finalidad de adentrarnos en la figura específica de abuso del derecho, contemplada dentro de las sentencias del Consejo de Estado y el tipo penal fraude de subvenciones estipulado en la Ley 599 de 2000. Nos preguntamos acerca del si existen diferentes tipos de sanciones para las personas que realizan estas conductas que pueden ser de orden punitivo, pecuniarias, disciplinarias o una combinación de estas y sobre cómo se ha abordado desde la perspectiva del derecho comparado.

La justificación de la presente revisión jurídica se aborda desde una panorámica dada por el tipo de regulación constitucional, como lo expresan los artículos 1 y 2 Superior en relación con la organización del Estado y los fines esenciales de este, los cuales son conducidos por los servidores públicos mediante el ejercicio de la función administrativa y con ello se comprende la manera en que la responsabilidad que se pregona sobre ellos, tiene un mayor grado de observación por realización de conductas omisivas o extralimitaciones de funciones consagradas en la legal o constitucionalmente.

Son ejemplo de ello la Ley 599 de 2000 y la existencia de tipos penales como el art.
170.5. sobre las circunstancias de agravación de la conducta punible del secuestro; el art. 179.2, 181.1., en cuanto a las circunstancias de agravación. Asimismo, el art. 14 de la Ley 1474 de 2011, el cual expresa: “...Al servidor público que en ejercicio de las funciones de su cargo o con ocasión de ellas realice una conducta punible o participe en ella el término de la prescripción se aumentara en la mitad...." De lo anterior se colige que en efecto se da estricto cumplimiento al mandato del art. 6 Superior acerca de la responsabilidad de los particulares $y$, en este caso, de los servidores públicos. Si bien es cierto este principio constitucional no determina ni desarrolla exclusivamente este articulado como lo manifiesta la Corte Constitucional en Sentencia C- 908/13:

(...) Es al Legislador a quien le compete determinar la responsabilidad de estos y la forma de hacerla efectiva; la responsabilidad por los daños antijurídicos causados por el Estado o por uno de sus agentes; la posibilidad de solicitar a la autoridad competente aplicar sanciones penales o disciplinarias por las conductas de las autoridades administrativas, ninguna autoridad administrativa podrá ejercer funciones diferentes a las encomendadas por mandato constitucional o legal (...). (Corte Constitucional de Colombia, 2013)

Con ello se quiere decir que de la realización de conductas contra legem se derivan los diferentes tipos de sanciones y de responsabilidades civiles, penales, contractuales, fiscales, patrimoniales y disciplinarias, pero este tipo de conductas deben ser analizadas conforme a las funciones constitucionales y legales que le fueron encomendadas para definir el grado de responsabilidad de este, pues no se puede incurrir en una responsabilidad fiscal si este funcionario no maneja recursos públicos. Lo anterior respondería a un principio de legalidad lato sensu, conforme a que las actuaciones deben ceñirse a la ley, salvo que por extralimitación de funciones pueda ser sancionado por dicha conducta, lo que es el principal objetivo de este análisis. 
Inclusive para el correcto análisis de tipicidad o de legalidad de las normas hay que desglosar el concepto de servidor público, del cual nace una subdivisión: Los trabajadores oficiales y los funcionarios públicos. Hay que mencionar, además que durante la vigencia de la Constitución de 1886 no existía esta subdivisión; actualmente lo está, permitiendo realizar una diferenciación con base en algunas características: los trabajadores oficiales son aquellas personas que trabajan para el Estado, fruto de una relación contractual para dar cumplimiento a una actividad misional, sin perjuicio de las relaciones contractuales que puedan existir como la prestación de servicios, los contratistas del Estado o los mismos particulares, que aunque no atañen, vale recordarlas. Literalmente la existencia del funcionario público tiene la característica de no ser fruto de relación contractual sino constitucional, legal, de acto administrativo o reglamentaria.

Al examinar brevemente lo anterior, el funcionario público es aquel que trabaja con el Estado fruto de una relación legal y reglamentaria con un nombramiento y una posesión que se desglosa de la siguiente forma: a. La relación legal nace del juramento de cumplir la Constitución y las leyes; b. La relación reglamentaria refleja su cargo y las funciones a desempeñar, así como el sueldo a devengar; c. El nombramiento debe estar consignado por escrito donde acepta el cargo y, d. La posesión sobre este. Estos cargos en lo particular son de carrera administrativa, aunque hay excepciones como sucede con los de elección popular, los de libre nombramiento y remoción, los trabajadores oficiales etc.

En consecuencia, se ha expuesto de forma abstracta el principio de supremacía constitucional que reza el art. 4 Superior, que demuestra el cumplimiento de estos mandatos establecidos por el constituyente de 1991 y que son regulados por el Congreso de la República para su ejecución por parte de la rama ejecutiva. A su vez, se da claridad a algunos aspectos de la investigación, con el propósito de dar continuidad a otros elementos esenciales de las conductas desplegadas y sancionadas conforme a su naturaleza, o respetando la figura del Juez natural. Si bien es cierto, la ciencia jurídica kelseniana permite una mejor compresión debido al esquema jerarquizado de las normas dentro del Estado, siendo la principal la Constitución Nacional, sumada a la confrontación entre la corriente positivista e iusnaturalista que genera Kelsen en su obra, donde el gobierno de la sociedad se rige por leyes creadas por el hombre.

\section{MARCO NACIONAL DEL TIPO FRAUDE DE SUBVENCIONES DENTRO DE LA LEY 599 DE 2000 E INTERNACIONAL EN PAIISES INTEGRANTES DE LA UNIÓN EUROPEA}

El origen de las sanciones de las conductas delictivas tiene su génesis desde épocas muy remotas como el código de Hammurabi o el Codex de Manú en la India; sin embargo, la obra del Tratado de los delitos y las penas es un referente esencial para entender el origen de las sanciones proporcionales a la conducta desplegada por el agente.

Si la geometría fuese adaptable a las infinitas y oscuras combinaciones de las acciones humanas, debería haber una escala correspondiente de penas, en que se graduasen desde la mayor hasta la menos dura; pero bastará al sabio legislador señalar los puntos principales, sin turbar el orden, no decretando contra los delitos del primer grado las penas del último. (Beccaria, 2015, p.26)

Posteriormente varias escuelas como la italiana o la alemana permiten continuar con una corriente positivista, en especial esta última, representada por ilustres juristas como Claus Roxin y Günter Jakobs con la teoría de la imputación objetiva. No obstante, en Colombia la legislación interna adoptó los postulados de la escuela finalista de Derecho penal de Hans Welzel, cuya base se cimienta en la conducta típica, antijurídica y culpable, y la definición del delito como una acción realizada con la finalidad de obtener un resultado deseado. De forma que el Código 
Penal en su art. 9 contempla los elementos de la conducta punible seguido de los elementos de la dogmática penal para la realización de una correcta adecuación típica conforme a los postulados del Finalismo.

Así la teoría de imputación objetiva de Jakobs permite encuadrar la responsabilidad del agente partiendo de la teoría del delito para desembocar en la conducta objetiva delictiva. Por ende, parte de las bases: a. el riesgo permitido es una situación estática y normativa representa la idiosincrasia de la sociedad; b. principio de confianza que refleja una comparación entre actividades de división de trabajo de la cual se genera un lazo de seguridad o de un deber entre pluralidad de sujetos para sopesar el riesgo permitido; c. prohibición de regreso ${ }^{1}$ parte de un desarrollo sistemático en el Capítulo III de su obra, con la finalidad de generar un dique a la participación del agente tanto en conductas dolosas como imprudentes, pese al conocimiento de un suceso futuro y; d. competencia de la víctima, un juicio de valor que permite desentrañar el alcance de las conductas e inicio de la responsabilidad y la intervención de la víctima en cuanto a lo acaecido.

Respecto a la imputación objetiva de Claus Roxin el profesor Cancio Meliá (2001):

la sintetiza como un resultado causado por un agente que debe ser imputado a este como autor si y solo sí realiza un daño antijurídico preestablecido, se haya consumado y por último se encuentre dentro del tipo penal, es decir, exista tipicidad de la conducta. $\mathrm{Su}$ sistematicidad de exclusión: a. disminución de riesgo cuando el agente busca anular un resultado grave, empleando una conducta con un resultado leve sin la intención de afectar

1. Zaffaroni (2002) sostiene: ...Jakobs sostiene que se activa la prohibición de regreso (no puede haber imputación) si el deudor le paga a su acreedor sabiendo que con el dinero comprará un arma para matar a una persona, porque el deudor no se halla en posición de garante respecto de la vida de esa persona. Excluye la imputación aun por culpa, aunque el curso causal sea previsible. (p. 474) al sujeto pasivo ${ }^{2}$; b. el riesgo jurídico relevante ocasionado cuando la conducta del agente no crea un efectivo daño antijurídico; c. aumento del riesgo permitido cuando así el agente haya decidido actuar diligentemente el daño antijurídico se hubiese producido y; d. esfera de protección es la envoltura de las anteriores pues pese a haber cumplido con los requisitos sistemáticos la lesividad no existe si la norma penal no la contempla. (p. 44)

Teniendo en cuenta los elementos sustanciales de la conducta punible es posible realizar una segregación del tipo penal contemplado en el art. 403-A, Titulo XV Delitos contra la Administración Pública, Capítulo primero, del Peculado de la Ley 599 de 2000:

\section{Artículo 403-A. Fraude de subvenciones}

El que obtenga una subvención, ayuda o subsidio proveniente de recursos públicos mediante engaño sobre las condiciones requeridas para su concesión o callando total o parcialmente la verdad, incurrirá en prisión de cinco (5) a nueve (9) años, multa de doscientos (200) a mil (1.000) salarios mínimos legales mensuales vigentes e inhabilidad para el ejercicio de derechos y funciones públicas de seis (6) a doce (12) años.

Las mismas penas se impondrán al que no invierta los recursos obtenidos a través de una subvención, subsidio o ayuda de una entidad pública a la finalidad a la cual estén destinados.

Inicialmente en cuanto a los sujetos intervinientes en el tipo penal se verá que el agente corresponde tanto a servidores públicos como a particulares sin distinción

2. Roxin (2008) manifiesta que si el agente ve como una piedra vuela peligrosamente a la cabeza de otro $y$, aunque no la puede neutralizar, si logra desviarla a una parte del cuerpo para la que es menos peligrosa, pese a su causalidad no comete lesiones, al igual que tampoco las comete el médico que con sus medidas solo puede aplazar la inevitable muerte del paciente. (p. 365) 
alguna, pues no se exige cualificación, pero tratándose de delitos contra la administración pública se encontrará que el bien jurídico protegido cobija a la persona jurídica de derecho público, por cuanto es el Estado el que sufre el detrimento en forma directa.

Simultáneamente para una correcta tipificación se debe de usar un método de interpretación ad litteram de los elementos normativos que contiene este: a. subvención ha de entenderse la entrega de una suma de dinero o en especie particularmente a una persona jurídica o excepcionalmente natural destinado a una finalidad ${ }^{3}$; b. ayuda como acción que se realiza en situaciones imprevistas para cumplir con una finalidad como lo serían desempleados, damnificados o situaciones de desastres naturales; c. subsidio forma de ayuda o apoyo económico destinado a un sector de la sociedad como resultado de unas políticas públicas predestinadas y; d. recursos públicos ${ }^{4}$ como objetos de utilidad pública susceptibles de valor económico o que permiten acceder, obtener o desarrollar fines propuestos. Estos no son sinónimos incorporados en el tipo penal, aunque sí buscan cumplir con una misma finalidad, la de contribuir al desarrollo de los fines esenciales del Estado a nivel infraestructural y social. Es necesario recalcar acerca de la interpretación literal, prima facie porque guardan similitud ínfima aunque tienen aplicabilidad distinta, pues la primera lo es para las personas jurídicas en tanto las otras dos no, salvo que se disponga lo contrario legal o administrativamente.

Cabe abrir un paréntesis respecto de la palabra subvención, debido a su complejidad, palabra que alude a la entrega

3. Acepción que desarrolla estructuralmente Sánchez López (1997) como subjetivos corresponde al ente público adjudicador, el particular como persona natural o jurídica y objetivos la atribución patrimonial, el carácter no devolutivo y la finalidad que pretende (pp. 101-108).

4. Para el profesor Hernández Quintero, H. (2013) esta terminología se implementó en forma genérica con un fin teleológico, evitar inconvenientes a la hora de realizar una imputación para que de esta manera no sea nula si llegado el caso los dineros estén siendo administrados por un privado a favor del Estado (p. 47). de sumas de dinero, aunque Ruíz (2005) ofrece una visión más amplia de esta:

...nos encontramos con las llamadas en sentido genérico o subvenciones indirectas que generan un beneficio para el agente sin que se haya realizado la entrega; las virtuales como obtención de descuentos en cuota, intereses, preferenciales entre otras y; de dispensa para ciertas obligaciones cuyo cumplimiento supone un determinado sacrificio patrimonial. (p. 141)

Con base en lo anterior cabe la pregunta ¿es posible que conforme al art. 403-A pueda existir este tipo de modalidades dentro del elemento normativo subvención? La respuesta sería que sí es posible encajarlas dentro de este delito, por cuanto todas estas acciones cumplirían con el verbo rector: obtener, sin importar el tipo de beneficio que obtenga el agente con el despliegue de su conducta, más aún porque la acción no especifica recibir, por ende, con solo obtener el respectivo acto administrativo que adjudique la subvención, ayuda o subsidio la conducta se consuma, de lo contrario existiría la figura de la tentativa. Para ilustrar lo anterior X suministra información, documentos o declaraciones a la Secretaría $\mathrm{X}$ para la obtención de vivienda de interés general y dentro del proceso de verificación se halla que la información es falsa.

Hay que mencionar además que el tipo penal no consagra que elementos configuran la conducta delictiva, sin embargo, establece un modo "mediante engaño de las condiciones requeridas" o "callando total o parcialmente la verdad", lo que lleva al ente acusador primero a identificar la norma que contempla la subvención, subsidio o ayuda a otorgar; segundo a precisar los requisitos para acceder a estos que pueden ser documentales, electrónicos o declarativos. Finalmente cotejará los elementos físicos, declarativos o digitales que se reputan falsos para probar el engaño o la supresión de información que hubiese impedido el acceso, en última instancia detallará la posible existencia de concurso de conductas punibles. 
La doctrina y jurisprudencia española contienen dos acepciones respecto de la conducta engañosa:

a. Subjetiva, aquel que determina en error a un tercero, aunque dicho error no hubiese pasado por alto en una persona mínimamente diligente engaño típico todo aquel que produce un error- y; b. objetiva, todo aquel que resulta objetivamente apto para producir error y es objetivamente apto cuando en términos generales el destinatario medio del mismo -objetivamente, mínimamente diligente- corre el peligro en incurrir en el a juicio ex ante de un observador objetivo. (Arroyo, 1987, p. 56)

Esto quiere decir que el engaño encausado ha de contener una apariencia de realidad y formalidad suficiente para engañar a una persona perspicaz y diligente en sus actividades con el fin de inducirla al error para obtener de esta forma el desplazamiento patrimonial a su favor, esta acepción hace parte de los reiterados fallos del Tribunal Supremo Español en cuanto a la figura del engaño. Seguidamente el objeto jurídico corresponde a la Administración pública como se ha mencionado reiterativamente dando salvaguarda a la actividad administrativa y a los fines esenciales del Estado; el objeto material realmonetario- al recaer sobre bienes del Estado.

Continuando con la desmembración de este tipo penal se hallará que se compone de un verbo rector compuesto: a. obtener llegar a obtener cierta cosa que se quiere, se solicita o se merece y; b. invertir emplear cierta cantidad de dinero en un proyecto o negocio. Por ende, la conducta del agente debe permear estos dos verbos rectores para que la conducta cumpla el requisito de la tipicidad, esto es, adecuada a la norma sustantiva que consagra el 403A, contrario sensu estaríamos frente a la posibilidad de una atipicidad absoluta o relativa, por consiguiente, la extinción de la presunta conducta delictiva. Lo anterior sin perjuicio de los dos elementos restantes de la dogmática penal como lo son la antijuridicidad y la culpabilidad.

La antijuridicidad como categoría dogmática penal desarrolla el principio de lesividad expuesto por la Sala Penal de la Corte Suprema de Justicia así:

"El principio de lesividad de la conducta punible surge como criterio de limitación al ius puniendi, de forma que permite tolerar a las autoridades toda actitud o comportamiento que de manera significativa no dañe ni ponga en riesgo a otras personas, ligado al bien jurídico protegido". (Corte Suprema de Justicia de Colombia, 2016)

En síntesis, la conducta debe generar un perjuicio considerable para que se le realice posteriormente el juicio de reproche a esta misma, porque de lo contrario carecería de la característica principal de esta categoría dogmática que sería poner en efectivo peligro los derechos abstractos que protege el Estado a través de la legislación penal. Lo complejo del asunto es delimitar hasta qué punto la antijuridicidad de la conducta pondría en efectivo riesgo los derechos abstractos protegidos sí como tal la norma no establece una cuantía determinada como sucede en otras legislaciones, en otras palabras, ¿cuál es el valor monetario, en especie o su equivalente dinerario que en realidad genera una afectación a la administración pública?

Por último, la culpabilidad cuando el agente mediante la comisión de la conducta dolosa o culposa tiene capacidad racional adecuada para comprender la finalidad de su conducta, aquí también se complemente esta esfera con el juicio de reproche ${ }^{5}$ que se le realiza por no haber obrado conforme a derecho, tener conciencia de la ilicitud de su conducta y en especial ser imputable y que, a su vez, no existan causales de exculpación, recordando que estas categorías deben ser concadenadas por lo menos hasta la antijuridicidad si se busca una sanción.

5. El doctor Torres Velásquez (2011) determina que el poder actuar de otra manera es el fundamento del denominado juicio de reproche que se le realiza al sujeto agente de la conducta típica y antijurídica (p. 609). 
Acto seguido, el tipo penal nos describe el modo en que el sujeto agente obtiene dichos recursos mediante engaño o callando total o parcialmente información verídica que puede impedir el acceso a estos recursos públicos, so pena de incurrir en las respectivas sanciones punitivas, aunque valga recordar que si el agente no invierte los recursos para su finalidad también será acreedor de esta. En este mismo orden otro rasgo importante a señalar tiene que ver con las sanciones o penas que consagra el tipo penal de lo cual se extracta que contiene dos penas principales que tácitamente se reflejan: la privativa de la libertad, la pecuniaria o multa y la privación del ejercicio de derechos y funciones públicas sin perjuicio de las penas privativas de otros derechos contempladas en el art. 43 y Ss. del Código Penal.

Con el objeto de avanzar en el marco internacional de la Comunidad Europea se recopila que alrededor de los años setenta se buscó implementar una unificación del Derecho Penal, como sucedió con el Congreso de Derecho Penal europeo, cimientos realizados en la capital belga en 1968. Así en este sentido Fernández Ogallar (2013) expresa: "Pese a intentos de unificar el Derecho Penal la comunidad europea no estaba dispuesta a ceder su ius puniendi en razón a que esta alianza tenía por objeto el mercado, empero, 1994 marca hito con la creación de bienes jurídicos" (p. 21). Profundizando en este campo se muestra que este paso conllevó primero a retirar el principal impedimento que tenía el surgimiento del actual derecho penal comunitario el carácter económico, que con la creación de la hacienda pública europea permitió el origen de este derecho con la finalidad de blindar estos recursos. Dicho esto, este eje estará compuesto por tres países: España, Italia y Alemania, de los cuales se examinará brevemente su legislación penal respecto de los tipos penales que puedan existir en relación con subvenciones $\mathrm{o}$ ayudas provenientes de entes públicos.

En primer lugar, la legislación española a través de la Ley orgánica 10 de 1995 contempla:
Art. 308

El que obtenga subvenciones o avudas de las Administraciones Públicas, incluida la Unión Europea, en una cantidad o por un valor superior a cien mil euros falseando las condiciones requeridas para su concesión $u$ ocultando las que la hubiesen impedido será castigado con la pena de prisión de uno a cinco años y multa del tanto al séxtuplo de su importe, salvo que lleve a cabo el reintegro a que se refiere el apartado 6 .

Las mismas penas se impondrán al que, en el desarrollo de una actividad sufragada total o parcialmente con fondos de las Administraciones públicas, incluida la Unión Europea, los aplique en una cantidad superior a cien mil euros a fines distintos de aquéllos para los que la subvención o ayuda fue concedida, salvo que lleve a cabo el reintegro a que se refiere el apartado $6 . .$.

...

Si la cuantía obtenida, defraudada o aplicada indebidamente no superase los cien mil euros pero excediere de diez mil, se impondrá una pena de prisión de tres meses a un año o multa del tanto al triplo de la citada cuantía y la pérdida de la posibilidad de obtener subvenciones o ayudas públicas y del derecho a gozar de los beneficios o incentivos fiscales o de la Seguridad Social durante el período de seis meses a dos años, salvo que lleve a cabo el reintegro a que se refiere el apartado 6... (Subrayados y negrilla fuera de texto original).

Del análisis realizado a los precitados numerales se puede extractar que guarda semejanza con la legislación colombiana salvo por la divergencia existente entre el Derecho Penal y Administrativo español especialmente con la cuantía de la subvención, de forma que si la cuantía no supera los $10.000 €$ el sujeto agente no será responsable penalmente al carecer de elementos sustanciales como tipicidad y antijuridicidad. Pese a esto, administrativamente se procederá a su 
recuperación, lo anterior sin perjuicio que pueden coexistir ambos procedimientos en caso de que se cumpla con la tipicidad de la subvención o ayuda recuperada administrativamente, la cual ha de tenerse en cuenta por parte del juez competente que adelanta el proceso penal. Algo que llama la atención respecto del mismo articulado, es que configura -tácitamente- el concurso de infracciones dentro del mismo, como lo son las falsedades instrumentales en las que incurrió el agente sino realiza el efectivo reintegro de la subvención o ayuda.

La Ley Orgánica 1/2019, de 20 de febrero, modifica de forma significativa el delito fraude de subvenciones, transformando la definición de unidad típica de acción, los referentes cuantitativos - siendo delictivas las conductas a partir de $10.000 €$ - la consideración homogénea de las subvenciones españolas $y$ europeas como objeto material del delito, la conexidad procesal o la prescripción. (Gabriel Rodríguez \& Ramos Laradia, 2019)

Ahora bien, en cuanto a los sujetos intervinientes en la conducta punible vemos que tampoco exige una cualificación dentro del mismo, por cuanto es posible que sea realizada por particulares, autoridades o funcionarios públicos como consagran algunos artículos $^{6}$ de la Ley orgánica y respecto a la acción o verbo rector el Derecho Penal español contempla dos: obtener y aplicar, sin los cuales la conducta vendría siendo atípica.

Alrededor de este asunto la corrupción juega un papel importante dentro del contexto del fraude de subvenciones como lo sostiene Javier Valls Prieto (2005):

Tanto en investigaciones de la $\mathrm{OLAF}^{7}$ como en sentencias del Tribunal de

6. v.gr. art. 322.2. Con las mismas penas se castigará a la autoridad o funcionario público que por sí mismo o como miembro de un organismo colegiado haya resuelto o votado a favor de su concesión a sabiendas de su injusticia. (Cursiva fuera de texto).

7, Oficina Europea de Lucha contra el Fraude. Órgano de investigación y control externo independiente, asimismo
Justicia de la Unión Europea y los interinos se detalla la intervención de funcionarios públicos en este delito... El sujeto activo casi siempre es funcionario público o autoridad en los casos de corrupción de las cuales distingue dos modalidades una pública en beneficio propio, de partidos políticos o sindicatos y otra privada dado particularmente por la preexistencia del cohecho (p. 54).

Continuando con este análisis el sujeto pasivo de la conducta recae directamente en los entes públicos y la Unión Europea así que los dineros pueden ser producto de recursos destinados a sanear o fortalecer determinadas actividades por parte de esta organización o en su defecto de dineros públicos. Es menester resaltar acerca de las penas para las personas jurídicas en cuanto al concurso de conductas como el ofrecimiento de dádivas o retribuciones que en este caso contempla penas graves. Igualmente, en cuando a la consumación de este tipo penal se puede inferir razonablemente que se da una vez se cree el acto administrativo que genera la asignación de la subvención o ayuda por cuanto es un prerrequisito, dado que sin este no obtendría dicho beneficio y la tentativa se configuraría hasta antes de la concesión de este.

Segundo, en la legislación italiana:

Art. 316-bis. Malversación de fondos en detrimento del Estado.

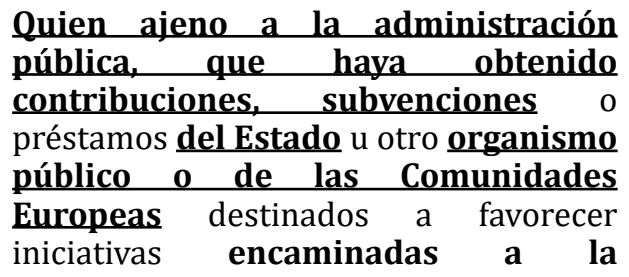
realización de obras o la realización

con facultad de investigar administrativamente los fraudes relacionados con fondos de la UE... Sin embargo, se considera un ente inquisitivo debido a sus amplios poderes investigativos, su independencia configura una Fiscalía General Europea, tanto así que acceden a locales u órganos de la comunidad sin previo aviso ni plazo, así como de interrogar e investigar en secreto por el tiempo que sea necesario. (Arroyo Zapatero \& Nieto Marín, 2016, p. 12) 
de actividades de interés público, no las destina a los fines antes mencionados, se sanciona con pena privativa de libertad de seis meses a cuatro años.

\section{Art. 316-ter. Recepción indebida de fondos en perjuicio del Estado.}

Salvo que el hecho constituya la infracción prevista en el artículo 640 bis, quien, utilizando o presentando declaraciones o documentos falsos o certificando hechos que no son ciertos. u omitiendo la debida información. obtenga indebidamente, para sí o para otros, subvenciones, préstamos. Los préstamos en condiciones favorables $\mathrm{u}$ otros desembolsos del mismo tipo, cualquiera que sea su denominación, concesión o desembolso por el Estado, por otros organismos públicos o por las Comunidades Europeas, son sancionados con prisión de seis meses a tres años. La pena es de prisión de uno a cuatro años si el delito es cometido por un funcionario público o un responsable de un servicio público con abuso de su calidad o facultades. La pena es de prisión de seis meses a cuatro años si el acto atenta contra los intereses económicos del Unión Europea y el daño o beneficio supere los 100.000 euros.

Cuando la cantidad indebidamente recibida sea igual o inferior a 3.999,96€, solo se aplicará la sanción administrativa de pago de una suma de dinero de 5.164 $€$ a $25.822 €$. En cualquier caso, esta penalización no puede exceder el triple del beneficio obtenido.

En efecto, esta legislación contempla dos tipos penales para la sanción de las conductas a la persona que destine la subvención encaminada a fortalecer obras o actividades de interés público, esto es, que el tipo penal sanciona al agente por el uso indebido de los recursos públicos dados para determinada finalidad, siendo necesario que para la comisión de la infracción debió haber recibido la subvención o ayuda. Consecuentemente el utilizar artificios $u$ engaños para obtener dicha subvención presentando información o declaraciones falsas, aunque se debe tener en cuenta que existe una subsidiariedad en cuanto al tipo como atañe al inicio de este, por ello debe desplegarse un efectivo juicio de valoración respecto al art. 640-bis. Esto quiere decir que si la conducta desplegada no concurre en las formalidades de hecho y de derecho del artículo dará paso subsidiariamente al art. 316-ter.

Nótese que el primer artículo precitado no exige cualificación alguna, a pesar de que en el segundo inicia excluyendo cualificación alguna del agente, más sin embargo en el mismo inciso establece la cualificación de funcionario público extralimitando sus facultades o la calidad que posee. Por ello, realizando un cotejo con la anterior legislación se encuentra conexidad en cuanto a la máxima suma de dinero (100.000€) y en cuanto a la mínima, corresponderá a $3.999,96 €$, dando paso a la jurisdicción administrativa para imponer la sanción respectiva a la contemplada en el inciso final del art. 316-ter cuando la cifra sea inferior a esta. Por último, si bien ha de hacerse tomar tangencialmente las acciones sancionadas, para el primero corresponde a obtener y para el consiguiente, se habla de acciones compuestas como: utilizar, presentar, omitir y obtener.

Por último, se retoma la legislación alemana:

\section{Art. 264 Estafa de subvenciones}

(1) Con pena privativa de la libertad hasta cinco años o con multa, será castigado quien,

1. suministre para sí o para un tercero datos incorrectos o incompletos sobre hechos relevantes de la subvención, que sean ventajosos para sí o para otro, a una autoridad competente para la aprobación de una subvención o a otra dependencia o persona (otorgante de la subvención), competente para la concesión de la subvención, 
2. deje al otorgante, en desconocimiento de hechos relevantes sobre las subvenciones, en contra de las disposiciones legales sobre la adjudicación de subvenciones,

3. utilice en un proceso de subvenciones un certificado sobre un derecho a la subvención o sobre hechos relevantes de la subvención, conseguido por medio de datos incorrectos o incompletos.

Esta legislación es más compleja y extensa en cuanto a la descripción minuciosa de la conducta del agente y de sus respectivas sanciones. Nuevamente, realizando una breve segregación de la conducta punible sobre las subvenciones ${ }^{8}$ vemos que no exige cualificación alguna del agente y que se compone de acciones compuestas para la comisión de este. Además, la legislación contempla sanciones más duras ${ }^{9}$ contra el agente que obtiene una subvención en grandes proporciones, abuse del cargo para su obtención, así mismo como la negligencia será sancionada ${ }^{10}$.

\section{FIGURA DEL ABUSO DEL DERECHO, PRECEDENTES DE LA CORTE CONSTITUCIONAL Y APLICACIÓN DENTRO DE LA JURISDICCIÓN CONTENCIOSO ADMINISTRATIVO}

La jurisdicción Contencioso Administrativo más allá de dirimir los conflictos entre Estado-particulares,

8. (7) Subvención, en el sentido de esta disposición, es una prestación de medios públicos, según el derecho federal o de los Estados, o del derecho de las comunidades europeas, a empresas o industrias que por lo menos parcialmente 1 . Se otorga sin contraprestación según el mercado y 2 . Debe servir para el fomento de la economía

9. (5) Aparte de una pena privativa de la libertad de por lo menos un año, a causa de un hecho antijurídico según los incisos 1 a 3, el tribunal puede denegar la capacidad de ocupar cargos públicos y la capacidad de obtener derechos por elecciones públicas ( $§ 45$, inciso 2). Los objetos que se refieran al hecho pueden ser confiscados; se debe aplicar el § 74 a.

10. (3) Quien actúe con negligencia en los casos del inciso 1 , numerales 1 y 2 , será castigado con pena privativa de la libertad hasta tres años o con multa. también versa sobre temas sancionatorios y conflictos Estado-servidores públicos o entre entidades públicas. Dando así una perspectiva más profunda acerca del Derecho Administrativo dentro del ordenamiento jurídico colombiano como acto que regula la estructura del Estado y la función administrativa de este.

Considerando ahora que la función administrativa ha de entenderse como el conjunto de actividades y funciones que realizan las entidades públicas con el fin de dar cumplimiento a los fines esenciales del Estado o en palabras del profesor Sarria (1974):

La función administrativa es el conjunto de actividades que se ejercen de manera permanente, directa, practica e inmediata, para la satisfacción de los intereses generales de la comunidad, mediante actos administrativos de carácter particular, haciendo uso -si es necesario- de las prerrogativas del poder público, para logar los fines del Estado y de los fines que establece la ley cuando atribuye esa competencia, a saber, siempre estando subordinada al orden jurídico preestablecido. (p. 214)

Es necesario resaltar que la teoría del abuso del derecho se puede colegir de la siguiente forma:

A. La Corte Constitucional en Sentencia SU 631 de 2017 manifestó: El abuso del derecho, según lo ha destacado esta Corporación, supone que su titular haga de una facultad o garantía subjetiva un uso contrapuesto a sus fines, a su alcance y a la extensión característica que le permite el sistema. Se presenta cuando en el ejercicio de un derecho subjetivo se desbordan los límites que el ordenamiento le impone a este, con independencia de que con ello ocurra un daño a terceros. Es la conducta de la extralimitación la que define al abuso del derecho, mientras el daño le es meramente accidental.

B. La Corte Suprema de Justicia se ha apoyado en diversas sentencias (Sentencia 
ref. 5464 M.P. Carlos Ignacio Jaramillo del 23 de junio de 2000 de la Sala Civil de la Corte Suprema de Justicia ) en la doctrina del profesor Jorge Joaquín Llambias (1997) "...no es posible dejar que los derechos subjetivos se desvíen para el fin que han sido consagrados, y se utilicen como armas para explotar a los demás... si es legítimo el ejercicio de los derechos no puede tolerarse su abuso" (p. 158).

C. El Consejo de Estado Sección Cuarta rad.17107 (2014) por su parte y en lo particular (Consejo de Estado Sección Tercera, Sala Plena 3-SPU-825-2014) se basa en la doctrina del profesor Rengifo García (2004) "abuso del derecho es un control de los derechos, especialmente de propiedad, de crédito y de control a la autonomía privada... aunque puede presentarse en todos aquellos casos en que el ordenamiento entrega poder, prerrogativas o facultades a particulares" (p. 179). El autor sugiere para precisar si se está frente a la figura de abuso del derecho debe de tenerse en cuenta la finalidad del derecho por parte del interprete y establecer si el ejercicio resulto abusivo o tuvo la intención de causar daño contrastado de forma axiológica con la Constitución Nacional.

Dentro de este mismo contexto se puede colegir algunas características genéricas como: a. Debe ser ejercido por el titular del derecho; b. se aparta de la teleología del derecho legal-constitucional; c. implica la lesión de otro derecho sea de inferior o superior gradación (Pabón Almanza \& Mora Ramírez, 2014, p. 74). Situaciones previas que el individuo debe de poseer para configurar el abuso del derecho que como se expresó en el capítulo anterior puede darse por particulares o servidores públicos, aunque en el desarrollo se estructurara con más detalle mediante la jurisprudencia puesta a colación.

Teniendo en cuenta las anteriores exposiciones de los órganos de cierre de la jurisdicción colombiana hallamos variedad de conceptos doctrinarios y teóricos enfatizando en un punto común: la extralimitación de los derechos subjetivos de las personas. De esta forma la línea a seguir está frente a la Jurisdicción de lo Contencioso Administrativo con situaciones concretas que se presentan en el sistema de pensiones con la Unidad Administrativa Especial de Gestión del Pasivo Pensional y Contribuciones Parafiscales de la Protección Social (UGPP) quien se ha visto inmersa en diversas disputas mediante Acciones de Tutela ante la jurisdicción Constitucional. Algunas han llegado a manos de los magistrados de esta misma corporación bajo la regla específica del abuso palmario del derecho y, por otra parte, la simulación de actos jurídicos con abuso del derecho en la jurisdicción ordinaria.

Claro ejemplo se da con los aumentos desproporcionados en las mesadas pensionales. Empero, la Corte Constitucional en Sentencia T-034 de 2018 ha reiterado los precedentes y mecanismos que tiene la UGPP y demás administradoras pensionales para actuar frente a esta extralimitación de derechos subjetivos. En especial alude el Acto Legislativo 1 de 2005, art. 1, no obstante, la Sentencia SU 427 de 2016 ha sido marco referencial debido a la ausencia legislativa frente al Acto Legislativo precitado, dando paso de esta forma al art. 20 de la Ley 797 de 2003 sobre el recurso de revisión para las prestaciones obtenidas mediante irregularidades o con abuso del derecho, siguiendo el precedente jurisprudencial de la C-258 de 2013 de esta corporación. Adicionalmente el art. 251 de la Ley 1437 de 2011 establece el término que tienen las administradoras pensionales sobre las prestaciones obtenidas con abuso del derecho es de cinco (05) años contados a partir de la ejecutoria de la providencia.

Hecha esta salvedad, las acciones constitucionales de amparo contra providencias judiciales interpuestas son improcedentes, al no cumplir con el requisito de subsidiariedad -salvo que se trate del abuso palmario del derecho condicio sine qua non- puede ser resuelta de fondo por el juez competente.

La Sentencia C-258 de 2013 expresa: “... para que el abuso del derecho se configure el aumento en la mesada pensional debe ser 
desproporcionado y debe ser evidente que no corresponde a su historia laboral...."

En esta misma ilación la Sentencia SU 631 de 2017 establece:

En el ejercicio del derecho pensional pudo haber transgredido los límites del principio de solidaridad del sistema de seguridad social... generando ventajas irrazonables que ponen en riesgo a los demás afiliados del sistema de seguridad social... atentando contra la equidad y la sostenibilidad del sistema.

Lo anterior sienta el precedente que permite identificar las causales de existencia de la figura abuso del derecho: i. la presencia de incrementos pensionales ilegítimos mensualmente cuantiosos, que desfinancian el sistema pensional; ii. inexistencia de correlación entre la historia laboral y el reconocimiento pensional del beneficiario, permitiendo ver el excesivo incremento y; iii. que este beneficio este encaminado de forma evidente, inconfundible y a ultranza una ventaja irrazonable o incremento monetario significativo frente a sus pares.

A su vez, la simulación de actos jurídicos con abuso del derecho encuentra una de múltiples referencias en el precedente horizontal del Tribunal Superior de Distrito Judicial de Cali, en el cual resuelve el recurso de apelación teniendo en cuenta lo fáctico:

Seguros de Vida Suramericana S.A., demanda a Merlyn Yeimy Muñoz Obando $\mathrm{y}$ otros, en orden a que se declare la simulación absoluta del acto civil de matrimonio contenido en el registro civil de matrimonio Nro. 4279643 del 20 de junio del 2006, celebrado entre la demandada y el señor Anatolio Cerón Túquerres, por cuanto en realidad entre las partes no existió una verdadera y real voluntad de perseguir los fines esenciales derivados de contraer nupcias y con ello conformar una familia, sino enmascarar un acto jurídico para acceder a unos beneficios en calidad de cónyuge supérstite.
Ante esta situación el cuerpo colegiado ha resaltado que cualquier persona con interés, (Corte Constitucional, Sentencia T-574 de 2016) en que haya prevalencia entre el acto real y el aparente puede ejecutar la acción de simulación. En cuanto a la figura del matrimonio contemplada en la Constitución Nacional y en el art. 113 C.C. permite deducir que tiene una finalidad la unión y que en ausencia de los requisitos esenciales del matrimonio conlleva a precisar que este nunca existió o nació a la vida jurídica; esto es, la declaración de simulación absoluta con efectos ex tunc. Aunando en esta institución, legalmente solo puede disolverse conforme a los postulados del art. 140 C.C., ante todo, la jurisprudencia constitucional ha sido enfática en que no es el único medio para extinguir la vida jurídica del matrimonio, existiendo otras vías como sucede en el acto jurídico simulado tanto en vida como a ausencia de uno de estos ${ }^{11}$, estas situaciones jurídicas son las que la doctrina ha denominado matrimonios de complacencia, conveniencia o en blanco.

El verdadero objeto de los matrimonios de complacencia es obtener determinados beneficios en materia de nacionalidad y de extranjería, aunque también incluye adquirir una residencia en el país o la reagrupación de familiares en el Estado... particularmente celebrados mediante promesa remunerada con el acuerdo de que nunca existirá convivencia matrimonial ni voluntad de fundar o formar familia, para posteriormente iniciar el proceso de separación judicial (Ortega, 2014, p. 77).

De lo anterior se extrae que lo que se obtiene son intereses económicos, sociales y jurídicos, generando beneficios mutuos para los intervinientes en este acto. No obstante, el acto jurídico celebrado entre los contrayentes no está encaminado a cumplir con las finalidades de esta institución

11. Corte Suprema de Justicia STC11819-2019... Tanto la nulidad absoluta como la simulación del matrimonio puede ser invocada pese a la muerte de uno de los contrayentes y la consecuente disolución del vínculo. Toda vez que el matrimonio sigue produciendo efectos jurídicos y patrimoniales, por ejemplo, pensionales, por lo que se hace necesario los correctivos para que cesen estas defraudaciones. 
sino en obtener un provecho mutuo o individual como en el tema de los seguros o pensiones de viudedad. De forma que en la presente providencia judicial se confirma la decisión del $A$-quo por cuanto este tipo de matrimonios distorsiona los fines de esta institución, a expensas de satisfacer intereses particulares y con base en la sana crítica este Tribunal evalúa los testimonios, hallando inconsistencias entre los mismos. Esto lleva a definir implícitamente la figura de abuso del derecho, pues los sujetos en el caso sub examine hicieron de un derecho legal-constitucional un fin contrapuesto a su esencia o en palabras de la Sala Civil de la C.S.J. una desviación de la garantía subjetiva para lo cual fue consagrada.

\section{3. ¿COLISIÓN DE JURISDICCIONES RESPECTO DE LA ACTIVIDAD ADMINISTRATIVA? PRINCIPIO CONSTITUCIONAL NON BIS IN ÍDEM}

Dentro del Estado Constitucional de Derecho colombiano se habla de unos fines esenciales que se deben suplir por parte de los gobernantes para con los coasociados, formando armonía con el principio de la dignidad humana, replicado en todos los procesos legislativos. Con todo esto, la capacidad sancionatoria que tiene el Estado ius puniendi para con el bien jurídico protegido, la Administración Pública busca ser un mecanismo de última ratio para con estas conductas antijurídicas.

Cabe hacer un paralelo dentro de esta figura Contencioso Administrativo y el tipo penal 403-A de la Ley 599 de 2000:

a. En primer lugar, reiteramos que se debe a una extralimitación de un derecho subjetivo de la persona, por mandato constitucional, legal o contractual y, sobre la conducta típica, antijurídica y culpable, deducimos que guarda una similitud, pues es una transgresión a lo que un derecho objetivo prohíbe.

b. Sin embargo, como se aludió en la Sentencia SU-631 de 2017, en algunos casos la materialización de dicho comportamiento no causa un daño a terceros, pero sí se configura una tergiversación teleológica del derecho objetivo, mientras que el tipo penal fraude de subvenciones necesariamente pone en peligro el bien jurídico protegido, causando un detrimento a los recursos públicos de los que es titular el Estado destinados a un beneficiario, el cual obtiene provecho suministrando información incorrecta, adulterada o realiza una inadecuada implementación de estos.

c. En cuanto a las sanciones, podemos encontrar de orden disciplinarias para aquellos servidores públicos o particulares que desempeñen funciones públicas que enmarcan desde la inhabilidad, las multas y la compulsa de copias a otros entes investigativos. En tal sentido como se detalló en la segregación del tipo penal, la conducta no exige un agente cualificado para la comisión de la conducta, por ende, también es aplicable a cualquier persona natural o representante legal de una persona jurídica la comisión de este hecho. Pero ihasta dónde llevaría aplicabilidad la imposición de sanciones disciplinarias, fiscales, penales o de cualquier otra índole a una persona por la comisión de este tipo penal o la extralimitación de un derecho subjetivo?

En ese mismo contexto el principio non bis in ídem en sentido estricto manifiesta que un mismo hecho no debe ser sancionado más de una sola vez, vale decir, duplicidad de sanciones para con el mismo agente por los mismos hechos acaecidos. En este entendido, la Corte Constitucional en Sentencia C-554 2001 expresa:

La prohibición del non bis in ídem no acarrea la imposibilidad de que unos mismos hechos sean castigados por autoridades de distinto orden...En efecto, es posible que un mismo hecho pueda ser objeto de investigación y punición en forma independiente por parte de autoridades diferentes, puesto que la potestad sancionadora del Estado que se despliega en esos campos obedece a la necesidad de proteger bienes jurídicos de distinta naturaleza. 
Lo anterior conduce a dilucidar que el principio non bis in ídem permea todo el tipo de sanciones sean de orden: penal, contravencional, disciplinario, correccional, punición por indignidad política (conocido también por el anglicismo "impeachment", mediante el cual se le atribuye un grado de responsabilidad a altos funcionarios del Estado, como el Presidente de la República), entre otros, y que, en efecto es posible ser sancionado por el mismo hecho cometido por el agente en sí, teniendo en cuenta la finalidad del ius puniendi de cada autoridad sancionatoria. Para ejemplificar lo anterior el derecho penal sanciona las conductas delictivas del agente buscando la reinserción a la sociedad, mientras que el derecho disciplinario pretende mantener el desempeño diligente y eficiente de la función administrativa; por tanto, las teleologías de las sanciones son diferentes, lo cual conlleva a que sea admisible aplicar diferentes sanciones siempre y cuando no exista una doble finalidad de estas.

\section{CONCLUSIONES}

En conclusión, las legislaciones de estos tres países pertenecientes a la Comunidad Europea, guardan relación entre sí en cuanto a la claridad y especificidad de la conducta punible, así como prevé situaciones concretas que no dan facilidad al agente de eximirse de la responsabilidad penal, ya sea por una atipicidad absoluta o relativa, contrario sensu la legislación colombiana pese a que no describe detalladamente algunas características como elementos normativos, acciones en beneficio del agente como estas dos legislaciones europeas (española-alemana) permite a través de estos lograr la adecuada tipificación; además estos países guardan un elemento valioso dentro de estos tipos penales y es en relación con la existencia de precedentes jurisprudenciales de los altos tribunales estatales, a diferencia de Colombia que aún no se contempla precedente alguno en la Sala Penal de la Corte Suprema de Justicia.

En síntesis, no encontraríamos una colisión de jurisdicciones entre la figura administrativa y el tipo penal de fraude de subvenciones, sino que hallaríamos una especie de complementación en sí encaminadas armónicamente a dar cumplimiento al art. 2 Superior. Siempre y cuando no exista una finalidad doble al momento de dar aplicación a las respectivas sanciones, pues en este sentido la Corte Constitucional ha sido enfática en cuanto a la posibilidad de sancionar a un agente por el mismo hecho cometido, respetando el principio constitucional del non bis in ídem.

\section{REFERENCIAS BIBLIOGRÁFICAS}

\section{Legislativas}

» Acto Legislativo 01 de 2005. Por el cual se adiciona el artículo 48 de la Constitución Política. Art. 1. Julio 25 de 2005. D.0. No. 45.980. http://www.secretariasenado.gov.co/senado/basedoc/acto_legislativo_01_2005.html

» Código Civil de Colombia [C.C.]. Ley 57 1887, 15 de abril de 1887. Art. 113. D.0. No. 2.867. http://www.secretariasenado.gov.co/senado/basedoc/codigo_civil.html

» Código de Procedimiento Administrativo y de lo Contencioso Administrativo de Colombia [C.P.A.C.A]. Ley 1437 de 2011, 18 de enero de 2011. Art. 251. D.O. No. 47.956. http://www.secretariasenado.gov.co/senado/basedoc/ley_1437_2011. html\#PARTE\%20PRIMERA

» Código Penal de Colombia [C.P.]. Ley 599 de 2000. Art. 403-A. 24 de Julio de 2004. D.O. No. 44.097. http://www.secretariasenado.gov.co/senado/basedoc/ ley_0599_2000.html 
» Código Penal Español [C.P.]. Ley Orgánica 10 de 1995, 23 de noviembre de 1995. Art. 308. BOE No. 281. https://www.boe.es/buscar/act.php?id=BOEA-1995-25444

» Constitución Política de Colombia [Const.]. 7 de julio de 1991 (Colombia).

» Ley 1474 de 2011 de Colombia. Por la cual se dictan normas orientadas a fortalecer los mecanismos de prevención, investigación y sanción de actos de corrupción y la efectividad del control de la gestión pública. Art. 14. Julio 12 de 2011. D.O. No. 48128. http://www.secretariasenado.gov.co/senado/basedoc/ ley_1474_2011.html

» Ley 797 de 2003 de Colombia. Por la cual se reforman algunas disposiciones del sistema general de pensiones previsto en la Ley 100 de 1993 y se adoptan disposiciones sobre los Regímenes Pensionales exceptuados y especiales. Art. 20. enero 29 de 2003. D.0. No. 45.079. http://www.secretariasenado.gov.co/senado/ basedoc/ley_0797_2003.html

\section{Jurisprudencia}

» Consejo de Estado. Sección Cuarta. Sentencia Rad. 25000-23-27-000-200600963-02, C.P. Hugo Fernando Bastidas Bárcenas; 13 de noviembre de 2014. http://www.icdt.co/noticia_al_dia/ FEBRER02015/23\%20DE\%20FEBRERO\%20 DE\%202015/CEst_Sec4_17107_14.pdf

» Consejo de Estado. Sección Tercera. Sala Plena. Sentencia Rad. 20001-23-31000-2009-00199-01, C.P. Mauricio Fajardo Gómez; 28 de abril de 2014. https:// www.d1tribunal administrativodelmagdalena.com/images/Jurisprudencia/Consejo_de_Estado/41834.pdf

» Corte Constitucional. Sala Plena. Sentencia C-258 de 2013, M.P. Jorge Ignacio Pretelt Chaljub; 7 de mayo de 2013. https://www.corteconstitucional.gov.co/ relatoria/2013/c-258-13.htm

» Corte Constitucional. Sala Plena. Sentencia C-554 de 2001, M.P. Clara Inés Vargas Hernández; 30 de mayo de 2001. https://www.corteconstitucional.gov.co/relatoria/2001/C-554-01.htm\#: :text=Sentencia\%20 C\%2 D554\%2F01\&text=La \% 20prohibici\%C3\%B3n\%2 0del\%2 0non \% 20 bis,sean\%20apreciados\%20desde\%20perspectivas\%20distintas.

» Corte Constitucional. Sala Plena. Sentencia C-908 de 2013, M.P. Alberto Rojas Ríos; 3 de diciembre de 2013. https://www.corteconstitucional.gov.co/ relatoria/2013/C-908-13.htm

» Corte Constitucional. Sala Plena. Sentencia SU 631 de 2017, M.P. Gloria Stella Ortiz Delgado; 12 de octubre de 2017. https://www.corteconstitucional.gov.co/ relatoria/2017/SU631-17.htm\#: :text=SU631\%2D17\%20Corte\%20Constitucional $\% 20 \mathrm{de} \% 20$ Colombia\&text=El\%20abuso $\% 20 \mathrm{del} \% 20 \mathrm{derecho} \% 2 \mathrm{C} \% 20$ seg\%C3\%BAn,que\%20le\%20permite\%20el\%20sistema.

» Corte Constitucional. Sala Tercera de Revisión. Sentencia T 574 de 2016, M.P. Alejandro Linares Cantillo; 20 de octubre de 2016. https://www.corteconstitucional.gov.co/relatoria/2016/T-574-16.htm

» Corte Suprema de Justicia. Sala Civil. Gaceta Judicial. Tomo XLIII, pág. 310-316, M.P. Antonio Rocha; 30 de octubre de 193. https://cortesuprema.gov.co/corte/ wp-content/uploads/subpage/GJ/Gaceta\%20Judicial/GJ\%20XLIII\%20n.\%20 
1904-1913\%20 (1936- 1937).pdf

» Corte Suprema de Justicia. Sala Civil. Sentencia Rad. 5464, M.P. Carlos Ignacio Jaramillo; 23 de junio de 2000. http://consultajurisprudencial.ramajudicial.gov. co:8080/WebRelatoria/ csj/index.xhtml

» Corte Suprema de Justicia. Sala de tutelas. Sentencia STC11819-2019, M.P. Arnoldo Wilson Quiroz Monsalvo; 4 de septiembre de 2019. https://cortesuprema. gov.co/corte/wp-content/uploads/2019/09/STC11819-20192.pdf

» Corte Suprema de Justicia. Sala Penal. Sentencia SP-14190, M.P. José Francisco Acuña Vizcaya; 2 de noviembre de 2016 https://cortesuprema.gov.co/corte/wpcontent/uploads/relatorias/pe/b2nov2016/SP14190-2016.pdf

» Tribunal Superior de Distrito Judicial de Cali. Sala Civil. Providencia Judicial Rad. 76001 -3 1-03-005-201 6-00 16 1-0 1-321 I, M.P. Homero Mora Insuasty; 13 de marzo de 2019.

\section{Doctrinales}

»Altalex. (2020, 10 de junio). Derecho Penal Delitos contra la Administración pública (Trad. Por Microsoft translator). https://www.altalex.com/documents/ news/2014/10/14/dei-delitti-contro-la-pubblica-amministrazione

» Arroyo Zapatero, L. \& Nieto Martín, A. Fraude de Subvención en la UE y en el CP. Universidad de Castilla- La Mancha. 1el-fraude-de-sub-final.pdf (uclm.es)

» Arroyo Zapatero, L. (1987). Delitos contra la hacienda pública en materia de subvenciones. Ministerio de Justicia. https://books.google.com.co/ books?hl=es\&lr $=\& i d=06 \mathrm{gUEaF} \_\mathrm{d} s w C \& o \mathrm{i}=$ fnd $\& \mathrm{pg}=\mathrm{PA} 51 \& \mathrm{dq}=$ fraude $+\mathrm{a}+\mathrm{sub}$ venciones\&ots $=w Y 1 \times 0 p j 4 q-\& s i g=15 u N K o 5 a G U-A R i 1 J 1 H p g J f y o B A g \&$ redir esc $=\mathrm{y} \# \mathrm{v}=$ onepage $\& \mathrm{q}=$ fraude $\% 20 \mathrm{a} \% 20$ subvenciones $\& \mathrm{f}=$ false

» Atienza, M. (2010). Constitucionalismo, globalización y derecho. En M. Carbonell y L. García Jaramillo (Eds.), El canon neoconstitucional (pp. 573-589). Universidad Externado de Colombia.

» Beccaria, Cesar. (2015). Proporción entre los delitos y las penas. En M. Martínez Neira (Ed.), Tratado de los Delitos y las Penas (pp.25-27). Universidad Carlos III de Madrid.

» CANCIO MELIÁ, Manuel. (2001). Líneas básicas de la teoría de la Imputación Objetiva. Ediciones Jurídicas Cuyo.

» Comisión Nacional del Servicio Civil. (2017). Carrera Administrativa. https:// www.cnsc.gov.co/ observatorio/index.php/informacion-general/3-carrera-administrativa

» Fernández Ogallar, B. (2013). El Derecho Penal armonizado de la Unión Europea. Dykinson.

» GabrielRodríguez\&Ramos Laria(2019).Lanuevaconfiguracióndel FraudeaSubvenciones. Dialnet. https://dialnet.unirioja.es/servlet/articulo?codigo=6888667

» Gómez, JAR. (2005). Fraude de Subvenciones y Estafa: aspectos concursales. Anuario de la Facultad de Derecho Universidad de Extremadura. Dialnet. https:// www.google.com/ url?sa=t\&rct=j\&q=\&esrc=s\&source=web\&cd=\&ved=2ahUKE wjilOKJ7u_uAhVluVkKHdBVATsQFjAAegQIAhAC\&url=https\%3A\%2F\%2Fdialnet. unirioja.es\%2Fdescarga\%2Farticulo\%2F1390168.pdf\&usg=AOvVaw0Qulp2gmn wEcy2MaDoiOf0 
» Günter, J. (1997). Sociedad, norma y persona en una teoría de un Derecho penal funcional (trad. Cancio Meliá, Manuel). Ad-Hoc. (Primera edición 1996).

» Hernández Quintero, H. (2013). El nuevo delito de fraude a subvenciones. Derecho Penal Y Criminología, 34(96), 31-55. https://revistas.uexternado.edu.co/ index.php/derpen/article/view/3640

» López Díaz, C. (1999). Código penal alemán traducido al español. Universidad Externado de Colombia. https://perso.unifr.ch/derechopenal/assets/files/ legislacion/1_20080616_02.pdf

» Llambias, Jorge Joaquín. (1997). Tratado de Derecho Civil Parte General Tomo II. Perrot. (Decimoséptima edición).

» Montesquieu, C. (1977). Del espíritu de las leyes. Editorial Porrua S.A.

» Ortega Giménez, A. (2014). España: el problema de los denominados "matrimonios de conveniencia". Dialnet. https://dialnet.unirioja.es/servlet/ articulo?codigo $=4785976$

» Pabón Almanza, C. \& Mora Ramírez, A. (2014). Límites al ejercicio abusivo del derecho de retracto Inconstitucionalidad en la sobreprotección del consumidor. Con-texto Revista de derecho y economía, (41), pp. 67-86. Vista de Límites al ejercicio abusivo del derecho de retracto. Inconstitucionalidad en la sobreprotección del consumidor (uexternado.edu.co)

» Rengifo García, E. (2004). Del abuso del Derecho al Abuso de la Posición Dominante. Universidad Externado de Colombia. (Segunda Edición).

» Roxin, C. (2008). Derecho Penal. Parte General. Fundamentos. La estructura de la teoría del delito. Thomson, p. 365.

» Sánchez López, V. (1997) El delito de fraude de subvenciones en el nuevo Código Penal. Colex.

» Sarria, Eustorgio \& Sarria Barragán, Mauricio. (1984). Derecho Administrativo colombiano -general y especial-. Pequeño foro. (Novena edición).

» Torres Vásquez, F. (2011). Manual de Derecho Penal. Ediciones USTA.

» Unidad Administrativa Especial de Gestión del Pasivo Pensional y Contribuciones Parafiscales de la Protección Social (2020). Sobre la entidad. ¿Quiénes Somos? https://www.ugpp.gov.co/ nuestra-unidad

» Valls Prieto, J. (2005). El fraude de subvenciones de la Unión Europea. Dykinson.

» Zaffaroni, E. (2002). Derecho Penal. Parte General. EDIAR 